\title{
Chapter 15 \\ Feasibility Evaluation for Condominium Reconstruction by Means of the Application of Discriminant Analysis on Real Estate Data
}

\section{Toshihiro Hanazato}

\begin{abstract}
This paper discusses the application of discriminant analysis on real estate data as a feasible estimation method for condominium reconstruction. The proposed method was used in order to verify its prediction capacity managing data from the real estate and resulting in $89.4 \%$ accuracy. This method revealed and highlighted the structure of four explanatory variables in terms of prediction impact. Further, it has been clarified that only three out of these four explanatory variables mentioned above were selected and constantly used in order to explain each analytical model.
\end{abstract}

Keywords Condominium · Reconstruction - Renovation · Discriminant analysis · Real estate data Act for Smoothening Condominium Reconstruction - Act on Facilitation of Reconstruction of Condominiums

\subsection{Introduction}

\subsubsection{Background to the Problem}

In this study, "condominium" refers to an apartment-type residential building that is a reinforced concrete (RC) structure or steel-framed reinforced concrete (SRC) structure, with the rights of owners protected under the Act on Building Unit Ownership, etc. ${ }^{1}$

\footnotetext{
${ }^{1}$ The definition of the condominium according to the Ministry of Land, Infrastructure, Transport and Tourism is "A building where 2 or more unit owners exist with exclusive elements that are shared by residents, the site thereof and attached facilities" (extract from the part concerning single buildings on the Ministry of Land, Infrastructure, Transport and Tourism website). The structure of
}

T. Hanazato $(\bowtie)$

Faculty of Art and Design, University of Tsukuba, Tsukuba, Ibaraki, Japan

e-mail: hanazato@geijutsu.tsukuba.ac.jp

Y. Asami et al. (eds.), Frontiers of Real Estate Science in Japan, New Frontiers in

Regional Science: Asian Perspectives 29,

https://doi.org/10.1007/978-981-15-8848-8_15 
Fig. 15.1 Cumulative probability graph concerning the ages of reconstruction $(\mathrm{n}=85)$

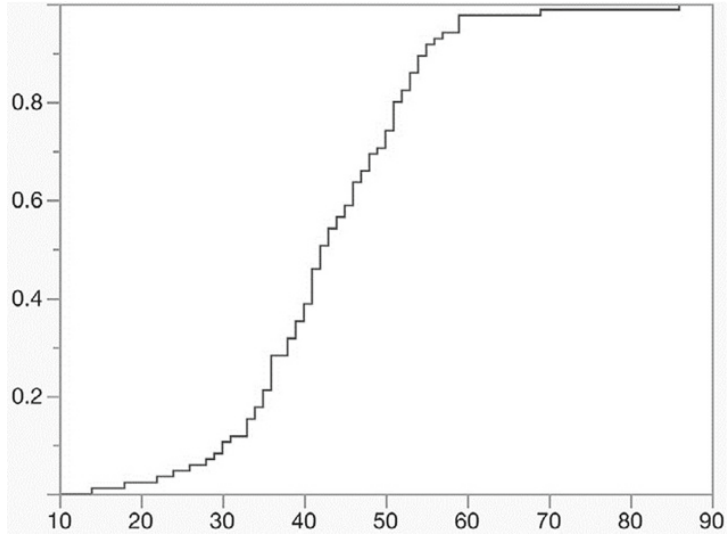

The period from the completion of construction of a condominium until its reconstruction is presented in the cumulative probability graph shown in Fig. 15.1. This by itself indicates the period for introducing condominiums coincided with World War II, so properties built 60-90 years ago are plateauing. However, apart from this, there is no other particular information to be obtained from the graph, which is just an ordinary cumulative probability graph.

These had an average life of 43.15 years with a median life of 42 years. $^{2}$

According to research on concrete carbonation (Sawaki et al. 2008; Tanuma and Sugiyama 2016), the physical life span of building concrete in RC structures such as condominiums is at least about 60 years, albeit there is a range. Rather than the deterioration of the building framework itself, condominiums often face the end of their life span due to social obsolescence.

In fact, given that condominiums are a fixture in modern society, rapid social changes and progress in science and technology may cause such position to change, and it is understandable that various forms of obsolescence are taking place. That is, there is a mismatch between technological progress and the continuing deterioration of buildings. In particular, there has been obsolescence in condominiums due to aspects such as earthquake resistance performance and barrier-free performance compared to when they were constructed. First, in terms of earthquake resistance performance, buildings constructed in or prior to 1982 were based on former earthquake resistance standards and are considered more susceptible to earthquakes when compared to the currently prescribed standards. In addition, obsolescence due to barrier-free performance is because there are many buildings without elevators in complexes with staircases. On top of this, the progress in the low birth rate and aging

the building is not designated here, but there is no mistaking that the definition is referring to durable RC structures, so we have defined as above.

${ }^{2}$ According to materials from the Ministry of Land, Infrastructure, Transport and Tourism, there was a total of 230 condominium buildings being reconstructed or prepared for reconstruction as at April 1, 2016. 
Table 15.1 Outline of the targets of the analysis

\begin{tabular}{|c|c|c|c|c|}
\hline $\begin{array}{l}\text { Analysis } \\
\text { model } 1\end{array}$ & \multicolumn{2}{|l|}{ Reconstruction } & \multicolumn{2}{|c|}{ Repair restoration } \\
\hline 132 & \multicolumn{2}{|l|}{85} & \multicolumn{2}{|l|}{42} \\
\hline $\begin{array}{l}4 \\
\text { classifications }\end{array}$ & $\begin{array}{l}\text { Uninterrupted } \\
\text { method }\end{array}$ & $\begin{array}{l}\text { Equivalent } \\
\text { exchange }\end{array}$ & $\begin{array}{l}\text { Large-scale } \\
\text { restoration }\end{array}$ & $\begin{array}{l}\text { Seismic resistant } \\
\text { repair }\end{array}$ \\
\hline 132 & 61 & 24 & 23 & 24 \\
\hline
\end{tabular}

population means phenomena such as the increase in vacant houses are also having a large impact.

There are various problems apart from the obsolescence caused by changes on an earthquake resistance basis and barrier-free performance. This includes many problems where, although the solution is currently known, a property cannot be retrofitted and needs to be reset. Reconstruction is considered an effective solution to such problems.

Reconstruction treats condominiums as things, but in reality, this is a human problem with various types of people participating in the process to form agreement itself. When there is a plan to reconstruct despite the lack of severe deterioration and obsolescence, there is also a large resistance from people with different opinions. In fact, when people involved in condominium reconstruction are asked, they say that the process of reaching agreement takes a lot of time and energy (Meno 2004). If reconstruction is to take place because of the life span, it becomes difficult to judge, and the available options face high hurdles, so people's judgments become divided. However, the main cause of obstructions to reconstruction is not clear even among researchers and reconstruction specialists, posing the issue as an open question by Tamura (2012). As noted above, there could be human factors, and there could be also important factors such as the problem of surplus floor area ratio and the building location, yet nothing is definitive. On the other hand, Ooki (2016) points to the large change in the prices of secondhand properties when there is reconstruction, and the advisability of reconstruction is discussed as having direct impact on the evaluation of the existing property prices. Therefore, comprehensively taking into consideration the aforementioned, he came up with a hypothesis that it was possible to evaluate the objective real estate data such as floor area and transaction price of existing properties as well as the pros and cons of reconstruction.

Therefore, this research does not delve into the reconstruction process, but hypothesizes that condominium reconstruction can be explained by using real estate data as an objective indicator. As already indicated, various factors are involved, so since it is unlikely to be able to explain by using a single factor, a discriminant analysis, one of the multivariate analyses, was conducted. 


\subsubsection{Review of Research}

The review of the research conducted on condominium reconstruction has shown a variety of past works. On the one hand, there is one that explained a project as a case study. For example, Higuchi (2016) discussed the process up until the reconstruction of condominiums on which he was involved as a consultant. The key points of project execution were explained from the perspective of individual circumstances, which is easy to understand. By contrast, an editorial by Fukui (2012) took a broader approach, looking at what policies were needed to be taken to deal with the social problems of condominium reconstruction, and also, it included thought-provoking suggestions. The former is researched from the perspective of people involved in reconstruction, particularly residents, whereas the latter is researched from a broader perspective. This paper takes the latter bird's-eye view approach to reconstruction. In addition, in terms of comparative legal research on reconstruction, Kamano et al. (2014) researched the legal systems for condominiums in European countries and the United States. While there are clear differences between countries, virtually no country has enshrined reconstruction in their legislation. At present, only some countries such as South Korea and Japan have taken independent initiatives concerning condominium reconstruction.

Various methods have been used in regard to the approach concerning the impact of the introduction of the Act on Facilitation of Reconstruction of Condominiums. Yunokihara et al. (2017) clarified the reconstruction methods and interviewed operators in an investigation of examples before and after the application of the Act on Building Unit Ownership, etc. The revision and the application of the Act on Facilitation of Reconstruction of Condominiums discussed how such legal revisions made reconstruction easier. Asami and Ishikawa (2012) discussed what sort of impacts the mitigation of the majority requirement, under the Facilitation Act, etc., had from a policy perspective. Furthermore, Osawa (2014) discussed this problem using data from a bird's-eye view of reconstruction as a whole.

In recent years, there have also been special editions discussing the difficulties of condominium reconstruction. Saito (2016), in a 2016 Special Edition of the Journal of the Japan Institute for Condominium Living entitled "Current status and issues for suburban condominiums," referred to an impending period of large conversion for suburban complex condominiums. On the other hand, Hasegawa (2002) asserts that complex condominiums are difficult to reconstruct because of factors such as the complicated relationship of rights in the certification as a single complex and their large scale.

Conversely, it could seem that a single wing condominium would be comparatively easy to reconstruct, but instead, there are few examples of evaluation research to date that have looked at the reconstruction of single wing condominiums and evaluated which have been easy to reconstruct. However, considering the large amount of stock of such single wing condominiums, the conditions that determine which are reconstructed will need to be clarified for there to be steady flow of reconstructions. 
In addition, in recent years, there have been announcements advocating the need for long-term management for a considerable period prior to reconstruction and special edition articles encouraging the importance of education to disseminate activities to owners of specialized knowledge (Hasegawa 2003, 2016).

In regard to condominium reconstruction, a "restoration ratio" 3 determined mainly by factors such as the surplus floor area ratio and construction costs and the market price of new construction in the vicinity of the condominium is often used as an indicator of the ease of project execution. However, this restoration ratio is also related to the construction costs and the proportion of dwellings left with the reconstruction; thus, it is not easy to understand before starting the project. In addition, there has not been enough discussion about what type of value has to be taken as the threshold value that enables judgment on the possibility of reconstruction.

There is also research attempting to handle the entire reconstruction from aspects such as cost. Meno (1998) selected three wards within the Tokyo Metropolitan Area, taking account of the matters such as the previous building attributes and the legal regulations in the area, to estimate the possibility of reconstruction costs. Onuma et al. (2009) and Kobayashi (2017) created a project of cost model for reconstruction simulation. A standardized restoration ratio, i.e., the burden amount for each unit owner, was calculated from conditions, such as the price of land and the floor area ratio, and graphed together with the price of land in the vicinity and the floor area ratio. It indicated the possibility of predicting the level at which people would select reconstruction based on a reasonable judgment.

In any event, an example of research using discriminant analysis to delve into the possibility of condominium reconstruction, as presented in this paper, has not been seen elsewhere (Hanazato 2017).

\subsubsection{Research Purpose}

The series of research, including this paper, is aimed at a round estimated number of condominiums with reconstruction possibility for a particular area through the application of discriminant analysis based on the real estate data for existing reconstructed properties.

The first step is to determine if reconstruction can be identified from condominium real estate data. The underlying propositions are as follow. The purpose is to confirm the outcome of "It is possible to identify condominium reconstruction from the past" (Proposition 1). The second step is to indicate the meaning of independent variables selected using the variable selection method for the condominium

\footnotetext{
${ }^{3}$ Floor area provided to the previous beneficiary with no cost is a percentage in relation to the floor area of previous rights, and $100 \%$ means the rights for the same area as in the past can be obtained at no cost.
} 
reconstruction project, with the purpose of clarifying that "The possibility of reconstruction can be estimated by combining real estate data that become the independent variables" (Proposition 2).

\subsection{Research Method and Target}

\subsubsection{Discriminant Analysis Procedures}

Discriminant analysis is an evaluation of feasibility for qualitative results taken from quantitative data. For example, it is used in the identification of the name of a disease from the numerical values of pathological examination (Ito et al. 1976; Ai 2016). At present, it is a method widely used in multivariate analysis such as in information processing.

Here, the attributes of "reconstruction" and "repair and renovate" for each example are used as the objective variable. On the other hand, independent variables, which are associated with the objective variable, are chosen for significant combination with covariates by a variable selection method through the analysis to address this.

That is, the procedures in this paper are first in Sect. 15.2 to separate examples into the "reconstruction group" and the "repair and renovate group" in order to compile real estate data for condominiums. In Sect. 15.3, discriminant analysis is conducted, and a prediction is made with the actual measured value of the analysis targets, to obtain the discriminant coefficient, i.e., the discriminant equation.

Next, in Sect. 15.4, condominiums which have not yet reconstructed are selected, and it is confirmed that it can be discriminated whether they shall be "reconstructed" or "repaired and renovated" by actually substituting real estate data into the discriminant equation. In Sect. 15.5, the results of analysis are interpreted.

\subsubsection{Targets of Analysis}

The objective variables used are the attributes of "reconstruction" or "repair and renovate" as shown below. Examples of targets of such analysis are categorized into two groups or four groups in Table 15.1.

\footnotetext{
${ }^{4}$ When the analysis was planned, the following points were taken to be stated conditions. First, the 230 examples of successful reconstruction are certain, but at the present point in time, the real estate data for only about 100 of these examples are available. In addition, they were primarily the cases that used the Facilitation Act, which account for more than half. To extract a corresponding control group or comparison group was difficult for the following additional three reasons. First, initially, it was completely unknown whether the reconstruction group could be identified through discriminant analysis, so there needed to be a group expected to produce a certain outcome for comparison
} 
Explaining the 4 groups, there are 61 examples of "Facilitation Act" group, which are all examples of condominiums that were actually reconstructed using the Act on Facilitation of Reconstruction of Condominiums that was enacted in 2002.

A comprehensive selection was made of the items that could be obtained from materials listed on the Mansion Saisei Association (Condominium Rehabilitation Association) website.

In addition, the "equivalent exchange" group refers to condominiums reconstructed with the equivalent exchange method in accordance with the provisions of the Act on Building Unit Ownership, etc. These were also mainly selected based on the materials of the Mansion Saisei Association. These two groups combined were chosen as the "reconstruction" group.

Furthermore, the 23 examples of the "earthquake resistance renovation" group and 24 examples of the "large-scale repair" group were created using data concerning the management status of old condominiums previously researched and published by the author and others (Hanazato 2014). These were examples of condominiums proactively selected from "earthquake resistance renovation" and "large-scale repair" forming a different group in terms of being selected separately from the "reconstruction group." Conversely, since reconstruction was judged to be difficult for reasons such as the existing disqualification of the floor area ratio, they can also be considered examples of "earthquake resistance renovation" and "largescale repair." In this paper, these two groups are combined as the "repair and renovate" group.

Observing the basic statistics for the condominiums area as the target of this analysis (Table 15.2), a number of average values are much the same for "reconstruction" and for "repair and renovate," yet others are quite different. For example, the change in the floor area ratio for "reconstruction" is nearly five times of "repair and renovate," while the previous gross floor area for "repair and renovate" is about twice of "reconstruction." In addition, the previous land appraisal value of each dwelling for "reconstruction" is about triple the level for "repair and renovate."

So, the examples of "reconstruction" and "repair and renovate" appear to have a certain bias that reflects their respective backgrounds.

\subsubsection{Twelve Covariates}

Twelve covariates were prepared as candidates for independent variables for the analysis.

purposes. Third, it was likely that the ease of reconstruction would differ by area, so it was not known how selecting a particular area would represent the total. Fourth, it was forecast that data would be very difficult to obtain. Since a certain degree of data was available for the earthquake resistance renovation group and the large-scale repair group, they were combined into the repair and renovate group and selected as the comparison group relative to the reconstruction group. 


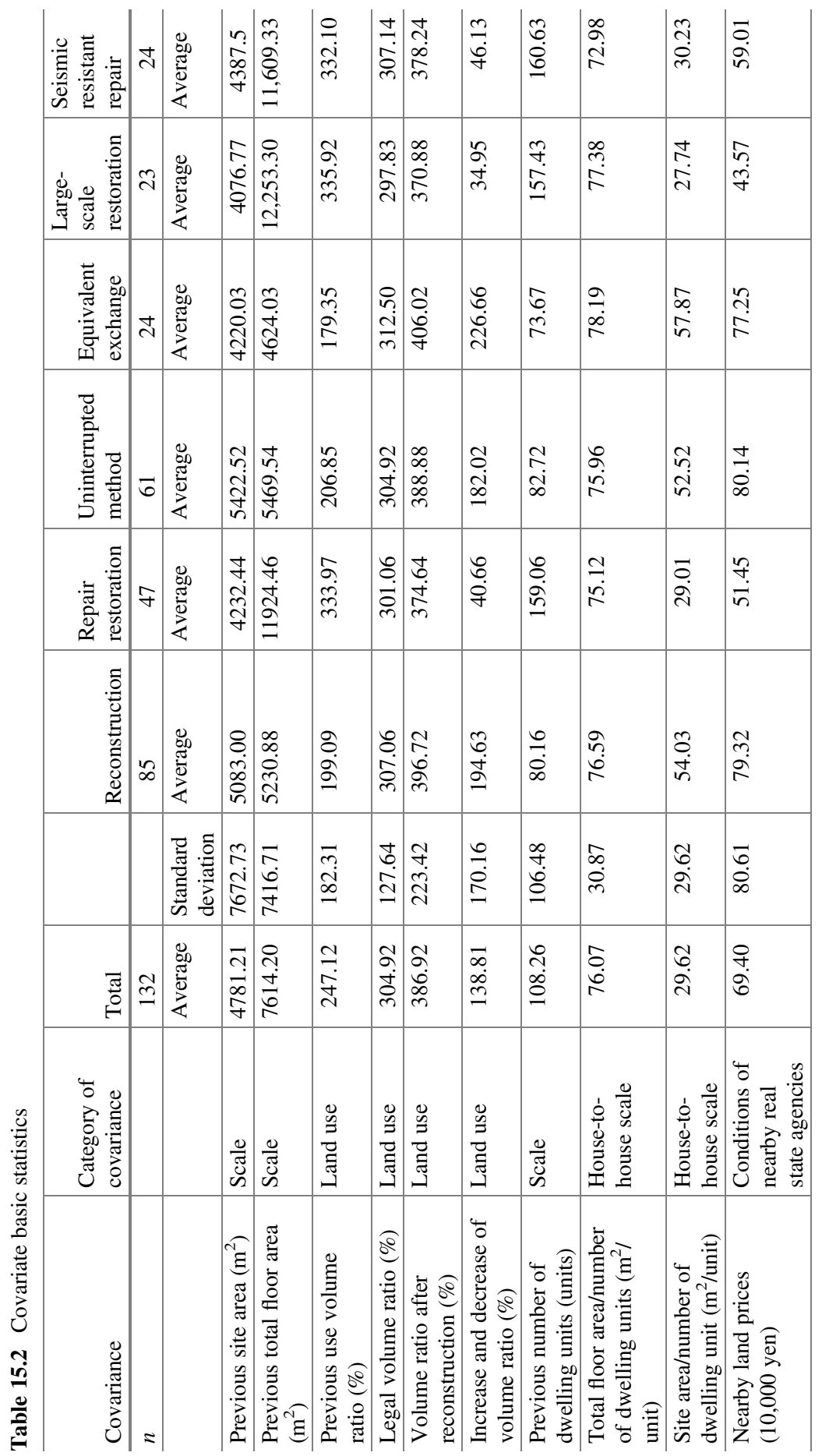




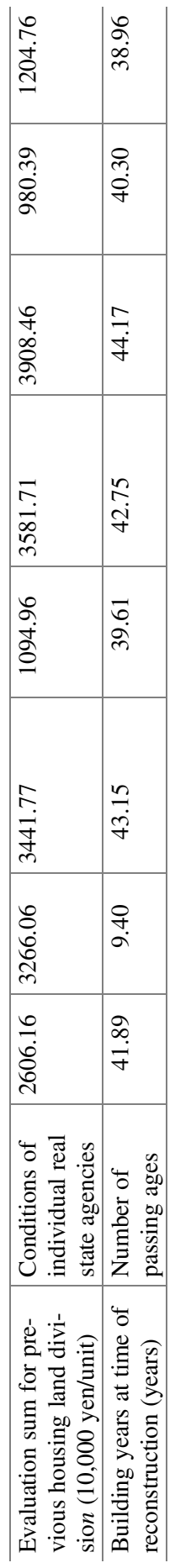


The categories of the aforementioned covariates are shown in Table 15.2. Thinking about subsequent stepwise selection, multiple covariates were prepared for each category.

Here, it is possible to identify respective covariates as being some form of proxy variable, that is, "legal floor area ratio," which can be considered a proxy variable corresponding to land use in the vicinity.

And "the previous land appraisal value for each dwelling" is thought to correspond to the condition of the real estate market; "the number of years since construction at time of reconstruction" is also a proxy for the proportion of elderly or the average age. Thus, it is possible to consider this as a proxy variable concerning residents' attributes.

Of the aforementioned 12 covariates, priority was given to the use of data obtained from the Mansion Saisei Association website. The calculation methods for items defined and guided by the author are, respectively, as follows:

"The previously used floor area ratio" is calculated by "the previous total floor area/the previous plot area." "The floor area ratio following reconstruction" uses the actual floor area ratio following reconstruction for reconstructed properties. Regarding to the not yet reconstructed properties, the legal floor area ratio is multiplied by a certain coefficient. In addition, "the change in floor area ratio" is taken to be "the floor area ratio following reconstruction minus the previously used floor area ratio." "The previous land appraisal value for each dwelling" is taken to be "the market value of land in the vicinity x previous plot area/number of dwellings."

\subsubsection{Discriminant Analysis Calculations}

The discriminant analysis calculations were done using ESUMI Co., Ltd.'s MAC Multivariate Analysis Ver. 3. The variable selection method used the stepwise backward selection method, with selection using the two in two out principle.

\subsection{Results}

\subsubsection{Results of Analysis}

In relation to the targets of analysis shown in Table 15.1, the four covariates from Table 15.3 were extracted as significant independent variables using the stepwise backward selection method: "the previous plot area," "the previous total floor area," "the change in the floor area ratio," and "the previous land appraisal value for each dwelling."

In addition, the null hypothesis was dismissed in regard to the results of the homoscedasticity and Box $\mathrm{M}$ inspection in Table 15.4 with different population 
Table 15.3 Discriminant equation

\begin{tabular}{l|l|l|l|l|c}
\hline & $\begin{array}{l}\text { Discriminant } \\
\text { coefficient }\end{array}$ & $\begin{array}{l}\text { Standardized } \\
\text { discriminant } \\
\text { coefficient }\end{array}$ & $\begin{array}{l}F \\
\text { value }\end{array}$ & $\begin{array}{l}P \\
\text { value }\end{array}$ & Judgment \\
\hline $\begin{array}{l}\text { Increase and decrease of } \\
\text { volume ratio (\%) }\end{array}$ & 0.000694 & -0.719 & 17.72 & 0.000 & $* *$ \\
\hline $\begin{array}{l}\text { Previous total floor area } \\
\left(\mathrm{m}^{2}\right)\end{array}$ & -0.000315 & -1.04 & 38.79 & 0.000 & $* *$ \\
\hline Previous site area $\left(\mathrm{m}^{2}\right)$ & 0.000181 & -1.87 & 11.29 & 0.001 & $* *$ \\
\hline $\begin{array}{l}\text { Evaluation sum for previ- } \\
\text { ous housing land division }\end{array}$ & 0.000176 & -0.264 & 4.023 & 0.047 & $*$ \\
\hline Constant clause & 0.1156 & & & & \\
\hline
\end{tabular}

n.s.: $p$ value $\geqq 0.05, *: p$ value $<0.05, * *: p$ value $<0.01$

Table15.4 Homoscedasticity and Box M inspection

\begin{tabular}{l|l}
\hline Chi-squared & 307.14 \\
\hline Degree of freedom (df) & 15 \\
\hline$P$ value & 0.000 \\
\hline Judgment & $* *$ \\
\hline
\end{tabular}

n.s.: $p$ value $\geqq 0.05, *: p$ value $<0.05, * *: p$ value $<0.01$

Table 15.5 Discriminant equation inspection

\begin{tabular}{l|l}
\hline Wilks' lambda & 0.506 \\
\hline Frequency & 9.68 \\
\hline Degree of freedom 1 (df1) & 12 \\
\hline Degree of freedom 2 (df2) & 119 \\
\hline$P$ value & 0.000 \\
\hline Judgment & $* *$ \\
\hline n.s.: $p$ value $\geqq 0.05, *: p$ value $<0.05, * *: p$ value $<0.01$
\end{tabular}

variances for both groups. ${ }^{5}$ Furthermore, as shown in Table 15.5, the null hypothesis was also dismissed for the inspection results of the discriminant equation, and this also appears to be statistically certain.

The discriminant score table is omitted. Fig. 15.2 splits the "reconstruction" group on the left and the "repair" group on the right, plotting the value of the estimated figures for a total of 132 condominiums in accordance with the discriminant scores.

"Reconstruction" and "repair and renovate" are identified as either 0 or more or below 0. As shown in the $n$ table in Tables 15.6, 15.7, and 15.8, 8/85 of the reconstruction group is below 0 and misjudged as "repair and renovate." On the other hand, 6/47 of the "repair and renovate" group are misjudged to be "reconstruction." These results are summarized in Tables 15.9, 15.10, and 15.11, with the

\footnotetext{
${ }^{5}$ As discussed in Sect. 15.2.2, this is thought to reflect the inability to guarantee the randomness of the control group, but this is anticipated considering the original purpose and assumed conditions of this paper. In addition, how to set the control group is the next issue.
} 
Fig. 15.2 Results of discriminant analysis concerning reconstruction possibility

Table 15.6 Discriminant cross table

Table 15.7 Horizontal \% table

Table 15.8 Vertical \% table

\begin{tabular}{l|l|l|l}
\hline & $\begin{array}{l}\text { Reconstruction } \\
(\%)\end{array}$ & $\begin{array}{l}\text { Repair restoration } \\
(\%)\end{array}$ & $\begin{array}{l}\text { Total } \\
(\%)\end{array}$ \\
\hline 0 or more & 90.6 & 7.1 & 62.9 \\
\hline $\begin{array}{l}\text { Less than } \\
0\end{array}$ & 17.0 & 87.2 & 37.1 \\
\hline Total & 100 & 100 & 100 \\
\hline
\end{tabular}

Table 15.9 Analytical precision

\begin{tabular}{l|c}
\hline Discriminant predictive rate & $89.40 \%$ \\
\hline Certainty of misclassification & $15.30 \%$ \\
\hline Mahalanobis squared distance & 4.1945 \\
\hline Correlation ratio & 0.494 \\
\hline
\end{tabular}

Table 15.10 Degree of realization

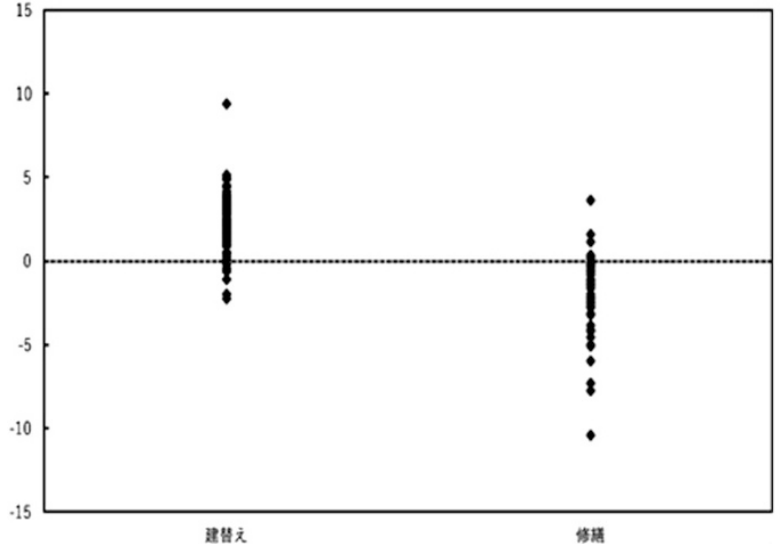

\begin{tabular}{l|c|l|c}
\hline & Reconstruction & Repair restoration & Total \\
\hline 0 or more & 77 & 6 & 83 \\
\hline Less than 0 & 8 & 41 & 49 \\
\hline Total & 85 & 47 & 132 \\
\hline
\end{tabular}

\begin{tabular}{l|l|l|l}
\hline & $\begin{array}{l}\text { Reconstruction } \\
(\%)\end{array}$ & $\begin{array}{l}\text { Repair restoration } \\
(\%)\end{array}$ & $\begin{array}{l}\text { Total } \\
(\%)\end{array}$ \\
\hline 0 or more & 92.8 & 7.2 & 100 \\
\hline $\begin{array}{l}\text { Less than } \\
0\end{array}$ & 16.3 & 83.7 & 100 \\
\hline Total & 64.4 & 35.6 & 100 \\
\hline
\end{tabular}

\begin{tabular}{l|l}
\hline Reconstruction & $92.8 \%$ \\
\hline Repair restoration & $83.7 \%$ \\
\hline
\end{tabular}


Table 15.11 Degree of predictability

\begin{tabular}{l|l}
\hline Reconstruction & $90.6 \%$ \\
\hline Repair restoration & $87.2 \%$ \\
\hline
\end{tabular}

degree of realization of "reconstruction" at $92.8 \%$, the degree of realization of "repair and renovate" at $83.7 \%$, and a discriminant predictive ratio of $89.4 \%$.

The discriminant predictive ratio which appears in the last above is the most general indicator of this analysis and shows a very high value at close to $90 \%$. This indicates that there is a relationship between real estate data and reconstruction possibility as well as providing proof established by Proposition 1.

\subsubsection{Discriminant Equation}

The discriminant equation to calculate each discriminant score was obtained as follows:

$$
y=0.000694 \times 1-0.000315 \times 2+0.000181 \times 3+0.000176 \times 4+0.1156
$$

(Here, $x[x 1$ : the change in floor area ratio, $x 2$ : the previous total floor area, $x 3$ : the previous plot area, $\mathrm{x} 4$ : the previous land appraisal value for each dwelling] is the variable indicated in the basic statistics shown in Table 15.2. $b$ is a constant term.)

\subsubsection{Misjudgment}

Taking into examination the misjudgements in the $n$ table shown in Table 15.6 and considering a concrete example in which "repair" was predicted, the actual measured value was "reconstruction," eight examples being Apartment E, Housing H, Condominium F, Complex I, Chateau M, Heights S, Condominium K, and Cooperative Housing $\mathrm{T}$.

In addition, the explanation of reverse misjudgments is omitted from a privacy perspective.

When the author and others separately interviewed consultants specialized in reconstruction, we realized that the process of reconstructed condominiums that were misjudged for "repair and renovate" included considerably difficult projects. Moreover, four examples that highlighted the restoration ratio are Apartment E 53\%, Housing H 83\%, Condominium F 19\%, and Complex I 83\%. Not only all of these fell short of the $100 \%$ restoration ratio that is sometimes considered the basis of reconstruction, but these also included the example of a $19 \%$ ratio for Condominium F. Therefore, this evidences that the projects were undertaken under considerably marginal conditions. 
Table 15.12 Details of Condominiums A, B, and C

\begin{tabular}{|c|c|c|c|}
\hline Apartment & A & B & $\mathrm{C}$ \\
\hline Location & $\begin{array}{l}\text { Takanawa, Minato- } \\
\text { ward, Tokyo City }\end{array}$ & $\begin{array}{l}\text { Nagatakita, Minato- } \\
\text { ward, Yokohama City }\end{array}$ & $\begin{array}{l}\text { Taga, Minami- } \\
\text { ward, Fukuoka } \\
\text { City }\end{array}$ \\
\hline Site area $\left(\mathrm{m}^{2}\right) \times 3$ & 2943.30 & $10,867.69$ & 4078.26 \\
\hline Floor area $\left(\mathrm{m}^{2}\right) \mathrm{x} 2$ & 8697.26 & 8226.00 & 7016.30 \\
\hline $\begin{array}{l}\text { Previous use volume ratio } \\
(\%)\end{array}$ & 295.50 & 76.00 & 172.00 \\
\hline Legal volume ratio (\%) & 350.00 & 150.00 & 150.00 \\
\hline $\begin{array}{l}\text { Available volume ratio } \\
(\%)\end{array}$ & 435.86 & 173.99 & 173.99 \\
\hline $\begin{array}{l}\text { Increase and decrease of } \\
\text { volume ratio }(\%) \times 1\end{array}$ & 140.36 & 98.30 & 1.95 \\
\hline $\begin{array}{l}\text { Number of dwelling units } \\
\text { (unit) }\end{array}$ & 73 & 140 & 81 \\
\hline $\begin{array}{l}\text { Units' total floor area } \\
\left(\mathrm{m}^{2}\right)\end{array}$ & 119.14 & 58.76 & 86.62 \\
\hline Units' site area $\left(\mathrm{m}^{2}\right)$ & 40.32 & 77.63 & 76.00 \\
\hline $\begin{array}{l}\text { Land-to-land asset evalu- } \\
\text { ation }(10,000 \text { yen) } x 4\end{array}$ & 4274 & 1335 & 1284 \\
\hline $\begin{array}{l}\text { Nearby land prices } \\
\left(10,000 \text { yen/m } \mathrm{m}^{2}\right)\end{array}$ & 106 & 17 & 25 \\
\hline $\begin{array}{l}\text { Number of built ages } \\
\text { (years) }\end{array}$ & 45 & 43 & 43 \\
\hline
\end{tabular}

\subsection{Discrimination of Condominiums}

\subsubsection{Outlines of Condominiums $A, B$, and $C$}

Here, we consider the linear discriminant model and actually substitute the data for three not yet reconstructed condominiums into the discriminant equation based on the predicted results of the analysis of the actual "reconstruction" examples and "repair and renovate" examples. The 12 covariates, including the 4 independent variables for Condominiums A, B, and C, are presented in Table 15.12. In addition, an outline is provided below for each condominium, including information other than the selected variables.

Condominium A is a small- to medium-sized high-end condominium comprising 73 dwellings that was constructed 45 years ago in Takanawa, Minato-ku, Tokyo. The total floor area per residence is just under $120 \mathrm{~m}^{2}$ in what is also a large-scale dwelling. The land asset appraisal value per residence is high at 42.74 million yen. Almost all of the $300 \%$ of legal floor area ratio is already used, but it is calculated that usage of a further $140 \%$ floor area ratio is possible due to regulatory revisions, etc. 
Condominium B is a medium-sized condominium comprising 140 dwellings built 43 years ago located in Nagatakita, Minami-ku, Yokohama City. The total floor area per residence is calculated to be more than $58 \mathrm{~m}^{2}$, and the land asset appraisal value per residence is calculated to be more than 13 million yen. In addition, the possible use floor area ratio is calculated to be about $100 \%$ in addition to the current floor area ratio.

Condominium $\mathrm{C}$ is 81 condominiums built 43 years ago in Taga, Minami-ku, Fukuoka. The total floor area per residence is calculated at more than $85 \mathrm{~m}^{2}$, and the land asset appraisal value per residence is calculated at just under 13 million yen. However, the possible floor area ratio available is calculated to be less than $2 \%$ more than the current floor area ratio.

\subsubsection{Prediction of Reconstruction}

Substituting these data into the discriminant equation outlined in Sect. 15.3 produces the results presented in Table 15.13.

Condominium A's discriminant score was 0.6135 with a positive value and the discriminant result as "reconstruction." Condominium B's discriminant score was smaller than A, presenting a positive value of 0.2805 , with a discriminant result also as "reconstruction." Condominium $\mathrm{C}$ was the only case with a negative value for the discriminant score of -1.090 and showing a predicted value for the discriminant result as "repair and renovate."

In this way, a discriminant result can be obtained by only substituting the necessary data into the discriminant equation.

\subsection{Interpretation of the Results}

\subsubsection{The Size of Independent Variables and the Positive or Negative Discriminant Equation}

The discriminant equation (Eq. (15.1) was obtained in Sect. 15.3.2. This equation shows that, of the discriminant coefficients, only a2, the previous total floor area, has a negative value, while the other three coefficients have positive values. It can be inferred if the entire $\mathrm{Eq}((15.1)$ is a negative, the discriminant will be "repair and

Table 15.13 Discriminant results

\begin{tabular}{l|l|l|l}
\hline Apartment & A & B & C \\
\hline Discriminant score & 0.6135 & 0.2805 & -1.090 \\
\hline Current status & In residence & In residence & In residence \\
\hline Predicted value & Rebuilding & Rebuilding & Repair restoration \\
\hline
\end{tabular}


renovate" (not reconstruction) and the value of the previous total floor area becomes larger, i.e., the larger the scale of the condominium, the more difficult the reconstruction becomes. Conversely, if the three independent variables other than total floor area become larger, it means an increase in the possibility of reconstruction.

Similarly, the relationship between the size of each independent variable and the positive or negative Eq. ((15.1), i.e., whether it is "reconstruction" or "repair and renovate," is summarized below:

(a) Change in the floor area ratio, i.e., in terms of what level of increase is allowed by law. The larger the value, the greater the possibility of reconstruction.

(b) The larger the total floor area, i.e., the larger the scale of the condominium, the smaller the possibility of reconstruction.

(c) In terms of the previous plot floor area, i.e., the larger the area of the plot, regardless of the size of the building, the greater the possibility of reconstruction.

(d) In terms of the appraisal value of the land for each dwelling derived from the previous total floor area for each dwelling, i.e., the higher the appraisal value, the greater the probability of reconstruction.

There is past research that reported similar results of (a) to (d), but an outcome of this research is the clarification of the respective weightings for the relationship among the four variables.

\subsubsection{Rearrangement of the Analysis Model}

Up until now, we have used the analysis model (1) in Table 15.1 that refers to "reconstruction" and "repair and renovate," and the ability to obtain a similar result based on slightly different data would signify the analysis results as stable. So, as indicated in Sect. 15.2, we looked at variations such as discriminant coefficient and predictive ratio when there is partial change to the analysis model.

"Reconstruction" can be changed to subsets of the Facilitation Act and equivalent exchange, while "repair and renovate" can be changed to earthquake resistance renovation and large-scale repair. Discriminant analysis of these was conducted with analysis models (2) to (6), as the combinations indicated in Table 15.14. For example, explaining in relation to "(5) the Facilitation Act $\times$ large-scale repair," facilitation is a subset of reconstruction, while large-scale repair is a subset of repair and renovate and a discriminant equation as the predicted results of such data can be derived. Note that like Sect. 15.3, it is confirmed by inspection that this is likely to be statistically certain.

As shown in Table 15.14, common independent variables are indicated as "change in the floor area ratio," "the previous total floor area," and "the previous plot area" for the discriminant equation in all analysis models. In addition, according to the difference in the analyzed model, the discriminant coefficients have the same positive or negative sign for all even though there are differences in the values. This indicates how it conforms to what was noted in the aforementioned (a) to (c). 


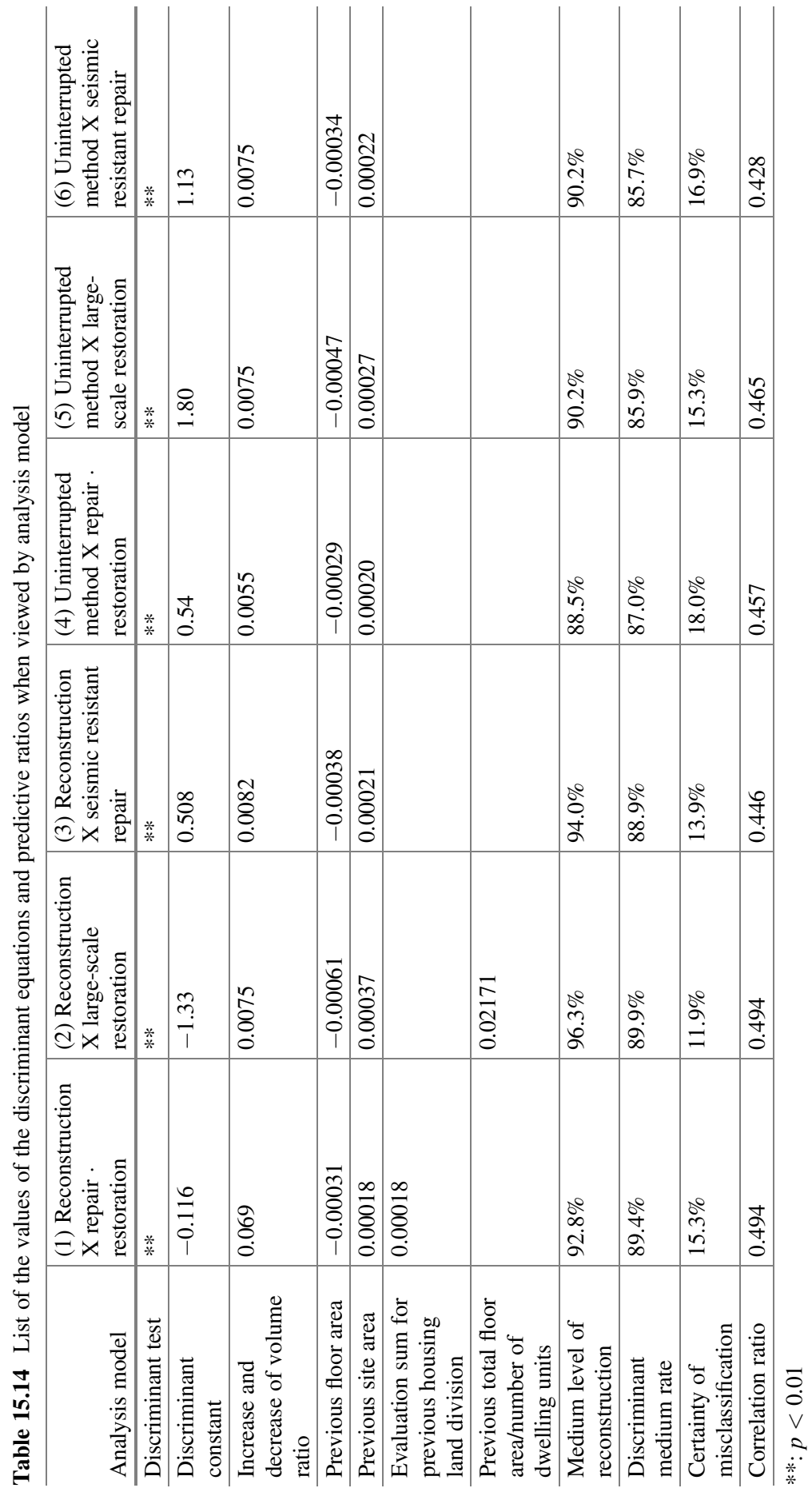


Furthermore, as evidenced above, there is the possibility that the four common independent variables mentioned are in fact proxy of some other variables, requiring further investigation.

\subsection{Concluding Remarks}

\subsubsection{Conclusion}

This paper can be summarized by the following five points:

1. This paper verified whether the feasibility of possible reconstruction could be evaluated on the basis of previous real estate data alone without touching on the reconstruction process.

2. A discriminant analysis was conducted collecting real estate data for the aforementioned purpose and taking "reconstruction" or "repair and renovate" as the objective variables.

3. As a result, in the learning process, "reconstruction" could be identified with a predictive ratio of $89.4 \%$. In addition, a discriminant equation was obtained consisting of four independent variables, i.e., the total floor area (scale of the condominium), the plot area (size of the plot), change in the floor area ratio (the extent to which there can be increased construction), and the previous appraisal value of land for each dwelling (asset appraisal value for the land obtained from the market land value in the vicinity).

4. Substitution of data for three examples of not yet reconstructed properties into the above discriminant equation was used to generate respective discriminant results.

5. When a discriminant analysis was conducted using an analysis model that is a subset by expanding it beyond (3) above, there were three independent variables for all of the models, that is, total floor area, plot area, and change in floor area ratio, were listed as independent variables.

\subsubsection{Conclusion}

Therefore, as indicated in the preceding paragraphs (3) and (4), the first purpose of answering the proposition of "It is possible to identify from the past" using real estate data was confirmed that it was possible. In other words, by first analyzing real estate data, it was feasible to confirm reconstructed condominiums out from the reconstructed condominiums and the renovated condominiums. In addition, it was also concluded that this could be quantified. In addition, regarding the second purpose concerning the question of "What combination of independent variables determines reconstruction," it was indicated from the preceding paragraphs (3) and (5) that four or three independent variables can be selected for many analysis models. Therefore, we can judge that the purpose was also achieved on this point. 


\subsubsection{Issues and Outlook}

As explained in Sect. 15.2.2, the data targeted for this analysis was adequate for comparative analysis purpose of the repair and renovate group with the reconstruction group, but it cannot be used to have any specific area representing all others. However, if one wants to calculate the number of condominiums that are possible for reconstruction from the number of deteriorated condominiums in City D, for example, the feasibility evaluation would be difficult just from the results obtained here. This is because the population in this paper (1) differs from the case of City D. To overcome this, it is necessary to select a more general population than the "repair and renovate" group used here.

Furthermore, this time, the analysis was conducted with virtually no consideration given to the attributes of the data in relation to the main human causes such as the approach of the management association and the age breakdown of residents. These must be incorporated in the future.

In addition, it has also been pointed out that consideration needs to be given to the possibility of other independent variables such as the prices of existing properties on the verge of reconstruction. It was not possible to reflect this due to the inability to prepare the data this time, but a major issue for the future is also the clarification of the relationship between the variety of covariates and the accuracy of prediction.

Acknowledgments This work was supported by JSPS Grant-in-Aid for Scientific Research (A) $27 \mathrm{H} 002811$.

\section{References}

Ai H (2016) Indexing of living environment attract young and productive age generation. J City Plan Inst Jpn 51(3):860-867

Asami Y, Ishikawa T (2012) Chapter 5 Average years to condominium reconstruction and the effect of relative measures. In: Condominium reconstruction: how do we prepare for the aging? Nihon Hyouron-sha, pp 115-132

Fukui H (2012) Chapter 2 Legal narrowness of reconstruction and management. In: Condominium reconstruction: how do we prepare for the aging? Nihon Hyouron-sha, pp 33-68

Hanazato T (2014) Reports on accumulation and analysis of succeeded examples which solved the issues of management and regeneration of condominium. NPO Housing Research Association of Tsukuba, Tsukuba, $55 \mathrm{pp}$

Hanazato T (2017) 5535, 5536 An execution of the analysis by the real estate data discriminant analysis on the rebuilding condominiums part I and II. In: Proceedings of an AIJ annual meeting, E-1, AIJ, pp 1069-1072

Hasegawa H (2002) Problems of 'the reconstruction rules for housing complexes'. In: Revised middle tentative plan for the sectional ownership low, Japan Housing Sciences, vol 38, pp $24-28$

Hasegawa $H$ (2003) The necessity of preparation from the management stage toward the smooth process of the condominium reconstruction: proposal of life-long management plan condominiums. Japan J Real Estate Sci 16(4):94-102 
Hasegawa H (2016) Proposal of long-term management plan for the smoother process of condominium reconstruction and the possibility of the usage of third-party specialist as committee members. Jpn Hous Sci 2016(93):139-144

Higuchi S (2016) A condominium reconstruction project in Fukuoka, Nissei Seishin Korporasu': conversion from two housings to one building. Urban Renew 554:37-42

Ito T, Muramatsu K, Okuma K (1976) Discriminant analysis using mesh method on land uses. Geogr Rev Jpn 49(7):470-479

Kamano K, Fujimaki A, Ito H, Funabashi S, Ohno T, Hanafusa H (2014) Mini symposium: international comparison of condominium law systems. Comp Law J 76:196-233

Kobayashi H (2017) How the rules for elimination of condominiums should be? To eliminate the difficulty of reconstructions. J Condominium Living 56:164-174

Meno F (1998) A study on project plan of reconstruction of condominiums - in case of typical building supplied by private enterprise in Tokyo ward area. J City Plan Inst Jpn 51(209):90-98

Meno F (2004) Characteristics of consensus building in reconstruction projects of deteriorated condominiums. J Archit Plan 69(582):117-123

Ohnuma Y, Iwata S, Minagawa K (2009) 8026 A study about the rebuilding possibility evaluation of the apartment based on land prices based on accessibility and construction cost. In: Proceedings of AIJ annual meeting, F-1, AIJ, pp 1269-1270

Ooki Y (2016) Issues to second hand market value of condominium which has renovation plans. Japan J Real Estate Sci 30(1):96-102

Osawa A (2014) Features and issues of floor area ratio relaxation system based on the condominium rebuilding facilitating low. Urban Issues Goto Yasuda Memorial Tokyo Res Institute 105:81-96

Saito H (2016) The realty and problems of condominiums found in suburban housing complexes. J Condominium Living 43(1):69-76

Sawaki D, Tanaka T, Kuroda I et al (2008) Characteristics of the concrete samples obtained from structures aged seventy years after their completions. Annu Select Pap Jpn Concrete Inst 30 (1):597-602

Tamura M (2012) Effect of the deregulation of condominium resolution for reconstruction on the condition of majority. J Condominium Living 43(1):69-76

Tanuma T, Sugiyama H (2016) Analysis on natural concrete carbonation of actual buildings and suggestion for its prediction method. J Struct Constr Eng 81(720):167-177

Yunokihara K, Nakajo Y, Saito H (2017) The influence that act on building unit ownership, etc. and act on facilitations on reconstruction of condominiums gave for the condominiums reconstruction. J Archit Plan 82(731):171-178

Open Access This chapter is licensed under the terms of the Creative Commons Attribution 4.0 International License (http://creativecommons.org/licenses/by/4.0/), which permits use, sharing, adaptation, distribution and reproduction in any medium or format, as long as you give appropriate credit to the original author(s) and the source, provide a link to the Creative Commons licence and indicate if changes were made.

The images or other third party material in this chapter are included in the chapter's Creative Commons licence, unless indicated otherwise in a credit line to the material. If material is not included in the chapter's Creative Commons licence and your intended use is not permitted by statutory regulation or exceeds the permitted use, you will need to obtain permission directly from the copyright holder.

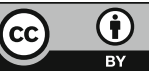

